\title{
Rethinking Space and Academic Identity Construction in A Higher Education Context: An Application of Mouzelis's Typology
}

\author{
Ms Nomanesi Madikizela-Madiya
}

University of South Africa

Email:madiyn@unisa.ac.za

Doi:10.5901/mjss.2014.v5n14p298

\begin{abstract}
Higher education has progressively adopted a corporate identity where teaching, research and related practices have become commodified, and academics are expected to practice for institutional financial gain. Academics have to develop programmes that attract as many students as possible. Research, teaching and related practices should be done in a way that secures funding for the university and attract subsidies from government and the industrial sector. Many academics complain of limited space for these practices. This article proposes a framework that academics may use to reflect on the issue of space for the development of their academic identities. The framework is drawn from Mouzelis's critique of structuration theory and highlights issues which may be considered as influential in academic practice as structure and agency.
\end{abstract}

Keywords: Space, higher education, academic identities, structuration

\section{Introduction}

Academics are expected to be productive in research, develop academic programmes that are attractive to students, be active in community engagement projects and produce more researchers through postgraduate supervision (HESA, 2012; Henkel, 1997). But, do they have the space and time that promote these practices? This is a question on which academics often reflect. It is common to hear comments from academics such as, 'I do not have enough space for all these expectations'; or 'I create my own time to do my academic work.' Such comments confirm that space and time are among the resources that can enable or constrain higher education practices and productivity (Cairns, Mclnnes \& Roberts, 2003; Lee \& Sawyer, 2010; Menzies \& Newson, 2007). On the other hand, such comments indicate that those in power do not always take space and time into consideration when they make demands for productivity on academics who are affected by space and time constraints. Lee and Sawyer (2010, p. 294) identify two extremes dominating the discourse on space and time which contribute to these tendencies: the first is the general perception that there is no need to consider space and time because they are a given or are 'just there', and the second is that macro-social scientists (such as Giddens, 1984; Adam, 1995) often make broad generalisations about time and space, which makes it difficult to develop empirical studies on these elements.

Of even more significance in the context of this article, however, is that even when academics reflect on the significance of space and time on their practices, they may only consider their agency as academics or the structures related to these. In the process, they may ignore other aspects that may affect their academic output and identity development. This is evident in the examples of comments I provided above where the first is an example of a structural consideration, while the second implies an agential consideration. However, if academic practices are to succeed and academic identities are to be developed as required, the reflection on the effect of space may require more than structure-agency considerations.

This article is premised on the notion that for academics to develop their academic identities and to meet the academic expectations, they need to reflect on more than whether they have a beneficial physical space (such as offices, parking space, library or other physical places) and an enabling metaphorical space. Metaphorical space in this case refers to academics' agency - their freedom and power to choose what and how to do things that develop their academic identities, the opportunities for them to grow academically, time to think and critically reflect, and be creative. Time therefore forms part of this metaphorical space. Thus from this point on, this discussion will refer to space as encompassing the dimensions mentioned above, including time.

Based on the notion mentioned above, in this article a framework which academics may use as they reflect on how space affect their practices and, thus, their academic identity development is proposed. The perspective that this article 
presents is informed by Mouzelis's (1995) critique of Giddens's (1982) structuration theory. The article draws from the theoretical framework of a study that analyses academics' perspectives of the role of space in the construction of their academic identities in a higher education context. After Lefebvre (1991), space in the study is theorised as multidimensional - physical, abstract, experienced and metaphorical.

The article is composed of five sections. Following this introduction is a brief discussion of the contentions of structuration theory in which an account of the concept of the duality of structure is presented. In the third section, Mouzelis's (1991, p. 95) critique of structuration theory, which highlights the shortcomings of the duality of structure, is discussed. Also, Mouzelis's typology of the orientations between structure and agency, in critique of structuration, is presented. Fourthly, the proposed framework that may be used for reflection on the effect of spatial structures on academic practices and academic identity construction is presented. The last section is the conclusion.

\title{
2. An Overview of Structuration Theory
}

Academic identity relates to "what academics do; what they should do; what they can do and what they want to do" (Professor Gerrit Kamper, informal conversation, 2012). This is, of course, not a standard definition of the concept academic identity, but from it I could identify the conditions of service (what they should do); and the options, choices, or freedom for academics (what they want to do). In his structuration theory, Giddens (1982) would define these two identifications as dualism and he would challenge it. Structuration theory challenges the dualism of subjectivity/objectivity which dominates research in social sciences and replaces it with the duality of structure.

Evidently, one of the significant concepts in Giddens's structuration theory is structure. Structure is composed of a set of rules and resources. Through these rules and resources, structure shapes or organizes people's actions because people use rules and resources in their actions. It is also the outcome of people's actions because the actions produce and reproduce rules and resources. This is what duality of structure implies - that structure and people's actions work hand in hand. In this way, there is no dualism between people's actions and structure; they are part of each other.

Giddens refers to people as "knowledgeable human agents" (Giddens, 1984). According to Sewell (1992, p. 4):

This conception of human agents as "knowledgeable" and "enabled" implies that those agents are capable of putting their structurally formed capacities to work in creative or innovative ways. And, if enough people or even a few people who are powerful enough act in innovative ways, their action may have the consequence of transforming the very structures that gave them the capacity to act.

Viewed in this way structure is not static, hence the concept 'structuration', suggesting a continuous process of creating structure. But what do these components of structure - rules and resources - mean?

Giddens (1982, p. 19) defines structure as "the structuring properties allowing 'the 'binding' of time-space in social systems, the properties which make it possible for discemibly similar social practices to exist across varying spans of time and space and which lend them 'systemic' form". Space forms part of the structure in a higher education institution (a social system) because, metaphorically, it is composed of rules. Rules are interpreted as the techniques, norms and procedures that guide people's actions (Sewell, 1992).

\begin{abstract}
Resources, another component of structure, can be authoritative "structured properties of social systems" upon which "knowledgeable agents" draw and reproduce as they interact (Giddens 1984, p. 15). Sewell (1992, p. 9) expands the explanation of resources and states:

Nonhuman resources are objects...that can be used to enhance or maintain power; human resources are physical strength, dexterity, knowledge, and emotional commitments that can be used to enhance or maintain power...Both types of resources are media of power and are unevenly distributed.
\end{abstract}

This way, power may be exercised by the actors and can also be exercised upon them through rules. As that power is exercised by, or upon actors, space is either created or limited. What, therefore, would structuration theory imply in the context of this article?

If academics were to follow the dominant subjectivity/objectivity debates in social science research to frame their reflections on the influence of space on their practices, there would be generally two major views. Some would regard space as structural and constraining, with academics having to conform to the rules and deliver as expected. An example of this view can been seen in Menzies and Newson's (2007; also, Winter, 2009) argument that academics have become highly stressed due to the conflicts between "scheduled time" and "time-less creative time". There has become too little of the time-less creative time and the university times are scheduled, a situation that resembles the corporate world. The concepts such as "value for money, managerialism, the knowledge industry, academic capitalism" are now much 
common in academe (Menzies \& Newson's 2007, p. 84). Menzies and Newson (2007, p. 84; also Becher \& Trowler, 2001 p. 11) argue that there is "transformation of relatively autonomous, self-governing academics into 'managed professionals' and 'state-subsidized entrepreneurs' conforming to 'fast-zone' tempo of business and politics". A recent survey conducted by the University and College Union (UCU) in 2012 in the UK, where 14000 higher education staff were involved, found an increasing feeling of loss of control by the academics on the way they worked (UCU, 2013).

These are structures that are viewed as constraining academic freedom, space in the context of this article. In these kinds of constraints it is not only the metaphorical space that is controlled, but sometimes also the physical space in cases where academics have to be in their offices on specified times. However, this article may not back this view because there is not much research done on the physical resources of higher education institutions (Yusoff \& Bilal, 2012), more so with research related to academics and their identity construction. This scarcity of research, in my view, does not mean that such physical resources are not important in higher education and its practices.

The second perspective that would dominate social science research would be that space is agential. Academics have agency (choice and freedom) to choose how to work in a way that develops their academic identities. For example Di Napoli and Barnett (2008) regard an academic, especially in the modern times, as someone who is able to voice her or his opinion without fear. Therefore, academics in this case may be able to plan space, especially the metaphorical dimension, in ways that are conducive to them.

However, Giddens (1984) structuration theory would challenge the dualism between these two opinions. For structuration theory, the rules related to space would affect academics' actions towards teaching, research and related practices. But these actions would also affect the rules in such a way that such rules might change due to the actions of influential academics in a particular higher education institution.

I agree with Giddens that structure and agency may in one way or another produce and reproduce each other. I also agree that agents may be knowledgeable in the sense that they may choose what to do and what not to do. However, after a study of Mouzelis' (1995) critique of Giddens, I found Giddens' duality of structure limiting on my endeavour to understand agent-structure relationship between academics and space in a higher education context. Below I present the structure/agency relationships according to Mouzelis (1995).

\section{More than the Duality of Structure: Mouzelis's Perspective}

Mouzelis $(1995,2011)$ critiques the original structuration theory. However, he does not completely distance himself from its assumptions. Instead he embraces both duality and dualism, arguing that they are both necessary in social analysis. In his view, actors may unintentionally draw from rules and reproduce them in the process. This would be the duality of structure. But, when they deliberately draw from rules, then that is dualism because rules would be deterministic of academics' actions or practices. According to Mouzelis, what needs to be considered is that as long as there are social hierarchies, where some people have more power than or over others, the orientations that actors have in relation to structure will be complicated. There will be sometimes dualism and sometimes duality of structure.

Like Giddens, Mouzelis (1995) argues for the acknowledgement of both the general 'virtual' rules (paradigm) and the 'actual' or observable application of rules (syntagm) in social analysis. He presents a typology that may assist academics as they reflect on their actions in relation to space as a structure. He argues that social analyses should distinguish between three dimensions of social action: role/positional, dispositional, and situational-interactional dimensions. First, when analysis considers the role/position dimension, the concern would be to look at how social positions that are part of a macro-institutional order contribute to shaping local interaction. Due to their roles/positions, some people have more opportunities to develop their identities through academic practices while some have limited opportunities. In this case, the agency of those who do not hold influential positions in a higher education institution does not interact with structures to support the development of academic identities. Therefore, duality of structure is not always possible.

Secondly, the dispositional dimension is the situation where actors bring to the 'game' a "set of generative schema" or dispositions (Mouzelis 2008: 194). The dispositions may include the upbringing, social skills, attitudes, norms, cultural and educational background, and class, to mention but a few. Mouzelis argues that it is not only the roles or positions that are in action in a 'game' but also these dispositions. To illustrate this point, Sibeon (2004: 102) argues:

The point here is that general life experiences affect how we act in any particular situation and the dispositional dimension helps us understand, for example, why it is that, though there may be many similarities in their role performances, no two teachers ever perform the role of teacher in exactly the same way.

In this case, actions and their outcomes are not necessarily dependent on structures. At the same time, outcomes are not dependent on agency in the example, because both teachers may have some agency but still perform differently. 
It is the individual's dispositions that matter. Therefore, little duality of structure can be identified in such a situation as well. However, Mouzelis (2008, p. 194) argues, "...just as the game rules are not followed automatically but are strategically handled by the players as required by the situational interactive context, so are players' dispositions". In other words, even though the dispositions play a role in the 'game', they may not work alone in the presence of institutional context or rule. It is when the dispositions and the rules of the institution interact in the 'game' that duality of structure may be evident. The implication here is that academics in the same academic level may, for example, have different patterns of performance in teaching, research and related practices, depending on their dispositions and the manner in which their dispositions interact with institutional rules. This relationship between dispositions and rules may not be similar for different actors in the 'game' due to varying dispositions.

Thirdly, Mouzelis (1992) highlights the significance of institutional situations and interactions in affecting social orders and practices. He argues that there are macro actors, people whose decisions lead to consequences that are widely felt over space and time (Mouzelis 1992, p. 123). Because of the extent to which these decisions stretch over space and time, they affect interactions at micro level, that is, between individuals at a local scale, such a faculty or department. Positions of power and "privileged access to the economic, political, and cultural means of social construction contribute more significantly to the construction of social phenomena than do those who do not enjoy such access" (Mouzelis 1992, p. 123). An example that may be given in this case is that of access to funding. Such access to or control of funding may determine the rate of development of an academic. Those who have limited access to funding, for example, have limited opportunities of networking with other academics in their field. Therefore, hierarchies and unequal positions of action may not be ignored.

Mouzelis's point is that both dualism and duality of structure may exist, depending on different situations in which the actors find themselves at particular times and contexts. There are two things to be considered about structures as the typology discussed above is examined in relation to the relationship between space and academic identity construction. Firstly, the rules that structures are composed of are both "virtual" and "actual". Virtual rules, according to Sibeon (2004) are paradigmatic. This may be interpreted as meaning that rules are presented as law to be followed. On the other hand, the actual and observable application of rules is syntagmatic. In other words, the application of rules is observable. Secondly, the manner in which an academic is positioned in relation to virtual structures determines the manner in which rules are applied. From this analysis of rules, Mouzelis identifies four possible forms of relationships between actors and structure: paradigmatic duality; paradigmatic dualism; syntagmatic duality and syntagmatic dualism.

First, paradigmatic duality is similar to Giddens' duality of structure where there is no distance or distinction between structure and agency (Mouzelis, 1991). Actors do not bother reflecting on the circumstances of their practice, but take the structural conditions for granted and act without analysing or reflecting on the rules (Mouzelis, 1995; Bagguley, 2003). The role/positional dimension discussed above is much in action in this situation because it is usually the actors who hold no powerful positions in the institution or organisation that have this kind of a relationship with the structures (Mouzelis, 1991). To illustrate what happens with paradigmatic duality, Bagguley (2003, p. 145) gives an example of the traditional working class where capitalist rules, division of labour or structurally determined wages would be accepted with very limited questioning or intention and power to transform them.

Secondly, there is paradigmatic dualism. This is where actors deliberately "distance themselves from the rules and resources, in order to examine them, or in order to build theories about them, or - even more importantly - in order to devise strategies for either their maintenance or their transformation" (Mouzelis, 1995, p. 616). This is again how actors in subordinate positions relate to "games played at higher organisational levels" (Mouzelis 1995: 120). In a higher education context, people higher up in the hierarchy of power may examine the patterns related to academics' research and students throughput, for example, and then decide to change things related to the number of academic staff, forms of technology in use, salaries and so and structure these differently. But those in the lower positions may not be able to significantly affect the "games" of the institution. They have limited space to do that.

Third, there is syntagmatic duality which occurs when the actors contribute significantly to the existence of the actual social system or social context such that "things would be significantly different (or impossible) without them" (Mouzelis 1995, p. 119). This now relates to the application of rules or structure that exists in an institution. Bagguley (2003, p. 146) explains the situation with syntagmatic duality that "...the social system is dependent upon the agents' continued action. If the individuals withdraw from the situation, then the system collapses". To illustrate syntagmatic duality, Mouzelis (1995, p. 119) gives an example of a participant in an academic seminar. He argues that "a participant may contribute so decisively to [the seminar's] major structural features that subject and social system are more or less inseparable; in such a case it is inconceivable to see such a social system as 'external' to the subject-participant". This way the actor becomes part of the social system and that system is not outside the actor. This situation is clearly interpreted in the discussion section below. 
Fourth, actors may have so little power that they may not be able to make any significant contribution towards change or transformation of a social system. "They would not be missed were they to leave" (Mouzelis, 1995, p. 119). In this case the orientation is syntagmatic dualism. The context in which the actor finds him/herself is external to the actor. "...the system is not dependent on the actions of the lower level individuals in the power hierarchy... it does not need their continued activity in order to continue functioning, or they are easily replaced" (Bagguley, 2003, p. 146). This way, an academic may not be able to change the influence of spatial structures on his/her practices.

The situations discussed above show how the relationship between space and actors, academics in this case, may not always be twofold in the same way as Giddens sees them in his duality of structure. This is what needs to be explored in relation to how space enables or constrains academics' practices in a higher education context. The discussion below attempts to provide a framework for such exploration.

\section{Reflecting on Space for Academic Identity Construction: After Mouzelis}

In the midst of changes or increasing demands on academics as they perform their practices in higher education, alternatives need to be identified on the manner in which space and academics' agency interact. In this section I use Mouzelis's typology to propose a framework for academics that may be used by academics to reflect on the relationship between their academic practices and space as a structure in a higher education institution context. This framework does not provide an easy way out of difficulties or constraints that may be experienced by academics in relation to space. Instead it leaves questions that I assume may be useful to reflect on and, which may be explored or examined.

First, institutions of higher learning have rules from which academics draw as they perform their teaching, research and related practices. If or when they draw from these rules and resources, they contribute to their reproduction or transformation. This would be an example of Mouzelis's paradigmatic duality. The rules and resources would have constituted both the medium and the outcome of the academic practices. Academics would have not questioned any of them, but acted accordingly. For example, if academics were expected to be in their offices for a certain duration or period of time, they would do so. If they were expected to publish one journal article per year, they would do so. This case relates to the role/position dimension referred to above in which the macro-institutional order shapes practices at a local or micro level. In other words, paradigmatic duality would be more experienced by academics that are lower in the power hierarchy of the institution. This is one way in which academics would relate to the institutional rules as they work within it. It is by no means the only way. Can this be a way to go? Can it help develop an academic's identity to just abide by the rules of the institution and do as informed? What are the alternatives?

Secondly, as Giddens (1984) suggests, academics are knowledgeable social agents. As such, there are situations where they would distance themselves from the institutional rules and resources in order to explore and see the difference between these and other ways and means that might be relevant for their academic identity construction. However, in terms of Mouzelis' paradigmatic dualism, it is mainly those who are higher up in the power hierarchy that would be able to do this. From this way of acting, academics would be in a position to compare the existing institutional rules and resources with their own ways of acting and build theories related to their comparisons and actions. Whatever they find from such explorations may lead to either maintenance or transformation of the institutional structures. In this context, an academic would be pro-active or innovative. As indicated above, this may apply mainly to those who have some amount of power. But, is it not worth exploring regardless of academic levels? For example, an academic whose structures specify or stipulate the number of hours to be spent in an office may think of ways of managing that time for the benefit of his/her academic identity. The question here would be what an academic does in each hour that he/she is in the office. The question to this might imply innovation or pro-activity for the benefit of a particular academic.

Thirdly, a particular academic may find that her/his actions of teaching, research and related practices do not produce the results that she/he intends to achieve. Students do not perform well in his/her course. Very little of her/his research gets published or very few postgraduate students graduate under her/his supervision. As the academic reflects on these outcomes it appears that they result from her/his style of work, such as the teaching methods, the writing style, and/or the way the academic relates to students. The results the academic gets are therefore not external to her/him as a subject. The relation between subject (the academic) and the object (the results from academic practices) is internal because the poor results could not exist independently of the weak methods the academic employs when doing things. The relationship that exists in this case is syntagmatic duality where the subject and the object are so closely interlinked that it would difficult to separate them. In this case the academic may not blame any dimension of the institutional space with regard to the results of her/his academic practices. This also relates to the dimension of dispositions mentioned above - the attitudes and beliefs on a particular academic. If, therefore, other academics experience similar spatial constraints but are advancing in their academia, the one who may find space not conducive may need to rethink the ways 
of addressing his/her dispositions for the benefit of his/her academic identity. This might include reflecting on how the academic was brought up in academe, how he/she has been doing the work in the past, and therefore what he/she needs to do differently.

However, if the conditions discussed in the third scenario above are the result of the authoritarian nature in which the institution operates, whether at a departmental, college or institutional level, then the result would be syntagmatic dualism. The example given by Mouzelis here is a case where all decisions about how academics should operate are made at a managerial level, a larger social system of which the academics' actions only form a part. In this case "...the authoritarian structural features of the college or university as a whole are clearly much more external to [the academic] as a situated subject; they probably existed before [the academic] became a teacher, and [the academic's] contribution to their reproduction is not as direct or as significant as [the academic's] contribution to the reproduction of the [academic's results'] structural feature" (Mouzelis 1995, p. 627). In addition, Mouzelis notes that the chances of this individual academic to transform the situation regarding the results of his/her practices are minimal because "the focus is on more inclusive social systems". In this case, the academic has limited or no space to freely choose how to do things and improve her/his identity. It would therefore be difficult for this academic to grow academically as quickly as academics that experience paradigmatic dualism for example. A number of proposals may be made in this case. Amongst these would be for an academic to use 'out of work' to network with other academics in different contexts to see how they deal with situations like his/hers.

\section{Conclusions}

The main purpose of this article was to propose a framework that may be used by academics to reflect on how space affects their practices in a higher education context. This proposal was motivated by the observation that academics are often complaining of limited space and time to develop their identities due to increasing work load and expectations. The discussion above indicates that due to power hierarchies and people's dispositions, there may be no single way of looking at the influence of space on academics. Each academic needs to reflect on his or her position in relation to space in the institution and think of possible ways of acting in that particular situation which may be positive for his or her academic identity construction. Academics may suggest what they think might be done to open their spaces and what they are doing or can do in the process. Is there really a way out? Research on this topic may bring some answers.

\section{References}

Bagguley, P. (2003). Reflexivity contra structuration. Canadian Journal of Sociology, 28(2), 133-152.

Becher, T. \& Trowler, P. R. (2001). Academic tribes and territories: Intellectual enquiry and the culture of disciplines. Buckingham: SRHE.

Cairns, G., Mclnnes, P. \& Roberts, P. (2003). Organisational space/time: from imperfect panoptical to heterotopian understanding. Ephemera, 3(2), 126-139.

Giddens A. (1982). Profiles and critiques in social theory. London: Macmillan.

Giddens A. (1984). The constitution of society. Cambridge: Polity.

Healy, K. (1998). Conceptualising constraint: Mouzelis, Archer and the concept of social structure. Sociology, 32(3), 509-522.

Henkel, M. (1997). Academic values and the university as corporate enterprise. Higher Education Quarterly, 51(2), 134-43.

Quarterly, 51(2), 134-43.

Lee H. \& Sawyer S. (2010). Conceptualising time, space and computing for work and organising. Time and Society, 19(3), $293-317$.

Lefebvre H. (1991). The production of space. Oxford: Blackwell.

Menzies H. \& Newson J. (2007). No time to think. Time and Society, 16(1), 83-98.

Mouzelis N. (1991). Back to sociological theory. London: Macmillan.

Mouzelis N. 1995. Sociological Theory: What Went Wrong? New York: Routledge.

Mouzelis N. (2008). Modern and postmodern theorising: bridging the divide. NY: Cambridge University Press.

Mouzelis, N. (2011. Restructuring structuration theory. The Sociological Review, 37(4), 613-635.

Sewell, W. H. (1992). A theory of structure: duality, agency and transformation. American Journal of Sociology, 98(1), 1-29.

Sibeon, R. (2004). Rethinking social theory. London: Sage

UCU. (2013). Academics stressed out by growing loss of control over workloads. A report of the 2012 survey. Accessed http://www.ucu.org.uk/6538 on 14 October 2013.

Winter, R. (2009). Academic manager or managed academic? Academic identity schisms in higher education. Journal of Higher Education Policy and Management, 31(2), 121-131. 